\title{
Activation of epithelial-mesenchymal transition process during breast cancer progression - the impact of molecular subtype and stromal composition*
}

\author{
Aleksandra Markiewicz'® ${ }^{\natural}$, Justyna Topa1, Marta Popęda1, Jolanta Szade², \\ Jarosław Skokowski ${ }^{3,4,5}$, Marzena Wełnicka-Jaśkiewicz ${ }^{6}$ and Anna J. Żaczek ${ }^{1 \otimes}$
}

1 Laboratory of Translational Oncology, Intercollegiate Faculty of Biotechnology, University of Gdańsk and Medical University of Gdańsk, Gdańsk, Poland; 'Department of Pathomorphology, Medical University of Gdańsk, Gdańsk, Poland; ${ }^{2}$ Department of Surgical Oncology, Medical University of Gdańsk, Gdańsk, Poland; ‘ Department of Medical Laboratory Diagnostics-Biobank, Medical University of Gdańsk, Gdańsk, Poland; ${ }^{5}$ Biobanking and Biomolecular Resources Research Infrastructure Gdańsk, Poland; ${ }^{6}$ Department of Oncology and Radiotherapy, Medical University of Gdańsk, Gdańsk, Poland

Breast cancer $(\mathrm{BC})$ is a heterogeneous disease with different molecular subtypes, which can be defined by oestrogen (ER), progesterone (PR) and human epidermal growth factor (HER2) receptors' status as luminal, HER2+ and triple negative (TNBC). Molecular subtypes also differ in their epithelial-mesenchymal phenotype, which might be related to their aggressiveness, as activation of the epithelial-mesenchymal transition (EMT) is linked with increased ability of cancer cells to survive and metastasize. Nevertheless, the reverse process of mesenchymal-epithelial transition was shown to be required to sustain metastatic colonization. In this study we aimed to analyse activation of the EMT process in primary tumours (PT), which have $(\mathrm{N}+)$ or have not $(\mathrm{N}-)$ colonized the lymph nodes, as well as the lymph nodes metastases (LNM) themselves in $88 \mathrm{BC}$ patients. We showed that luminal N- PT have the lowest activation of the EMT process $(27 \%)$, in comparison to $\mathrm{N}+\mathrm{PT}(48 \%, p=0.06)$. On the other hand, TNBC do not show statistically significant EMT activation at the stage before lymph colonization $(\mathrm{N}-, 83 \%)$ and after colonization of the lymph nodes $(\mathrm{N}+, 63 \%, p=0.58)$. TNBC are also the least plastic (unable to change the EMT phenotype) in terms of turning EMT on or off between matched PT and LNM (0\% EMT plasticity in TNBC vs $36 \%$ plasticity in luminal tumours). Moreover, in TNBC activation of EMT was correlated with increased cell division rate of the PT- in mesenchymal TNBC PT median $\mathrm{Ki}-67$ was $45 \%$ in comparison to $10 \%$ in epithelial TNBC PT $(p=0.002)$, whereas in PT of luminal subtypes $\mathrm{Ki}-67$ did not differ between epithelial and mesenchymal phenotypes. Profiling of immunotranscriptome of epithelial and mesenchymal luminal BC with Nanostring technology revealed that N- PT with epithelial phenotype were enriched in inflammatory response signatures, whereas $\mathrm{N}+$ mesenchymal cancers showed elevated MHC class II antigen presentation. Overall, activation of EMT changes during cancer progression and metastatic colonization of the lymph nodes depending on the PT molecular subtype and is related to differences in stromal signatures. Activation of EMT is associated with colonizing phenotype in luminal PT and proliferative phenotype of TNBC.

Key words: breast cancer, epithelial-mesenchymal transition, molecular subtypes, metastasis

Received: 01 June, 2021; revised: 18 July, 2021; accepted: 21 July, 2021; available on-line: 25 August, 2021 ๑e-mail: aleksandra.markiewicz@gumed.edu.pl (AM); azaczek@ gumed.edu.pl (AZ)

*This paper is dedicated to Professor Wacław Tadeusz Szybalski on the 100th anniversary of his birth

Acknowledgments of Financial Support: This work was supported by the National Science Centre grants number (2016/21/D/ NZ3/02629, AM and 2016/22/E/NZ4/00664, AJZ), National Centre for Research and Development, Bilateral Polish-Chinese program number WPC1/HESCAP/2019 (AJZ).

Abbreviations: $B C$, breast cancer; $E R$, oestrogen receptor; $P R$, progesterone receptor; HER2, human epidermal growth factor receptor 2; TNBC, triple negative breast cancer; EMT, epithelial-mesenchymal transition; PT, primary tumour; LNM, lymph node metastases; MET, mesenchymal-epithelial transition; TF, transcription factors; TWIST1, Twist-related protein 1; SNAI1 (SNAIL), Zinc finger protein SNAI1; SNAI2 (SLUG), Zinc finger protein SNAI2; ZEB1, Zinc finger E-box-binding homeobox 1; ZEB2, Zinc finger E-boxbinding homeobox 2; OVOL1/2, ovo like transcriptional repressors 1/2: GRHL 2, grainyhead like transcription factor 2; FFPE, formalin fixed and paraffin embedded; IHC, immunohistochemistry; VIM, vimentin; TMA, tissue microarrays; EPI, epithelial; MES, mesenchymal; DEG, differentially expressed gene; OS, overall survival; IFNy, interferon gamma; TNFa, tumour necrosis factor alpha; IL-6, interleukin 6; TGF $\beta$, transforming growth factor beta; IFITM2, Interferon Induced Transmembrane Protein 2; TRIF, TIR-domain-containing adapter-inducing Interferon- $\beta$; IFN $\beta$, interferon beta; PAI-1, Plasminogen Activator Inhibitor-1

\section{INTRODUCTION}

Breast cancer $(\mathrm{BC})$ is a heterogeneous disease with five different molecular subtypes - luminal (further subdivided to luminal A, luminal B HER2+, luminal B HER2-), HER2+, and basal subtypes/triple negative (TNBC) (Sarrió et al., 2008; Cancer Genome Atlas Network, 2012; Kast et al., 2015). These subtypes are the basis for prognostication and therapy selection. Of all the subtypes, luminal tumours, characterised by presence of hormone receptors, have the best prognosis (though they are also the ones which show late recurrence), whereas TNBC are more aggressive, with limited access to targeted treatment options (Hennigs et al., 2016). Apart from having different profiles of growth hormone receptors, molecular subtypes differ in their invasiveness, stem cell phenotype and therapy resistance, which was attributed to the activation of the epithelial-mesenchymal transition (EMT) (Mani et al., 2008; Morel et al., 2008; Felipe Lima et al., 2016; Shibue \& Weinberg, 2017; Katsuno et al., 2019). EMT is an early morphogenic program also activated under (patho)physiological conditions in adult tissues, which allows polarized and immobile epithelial cells to acquire features of motile mesenchymal cells 
(Thiery, 2002). Ability to invade surrounding tissues, a feature characteristic for invasive cancers, is increased in tumour cells with activated EMT program (Sánchez-Tilló et al., 2011; Lamouille et al., 2014). Undergoing EMT and the reverse process of mesenchymal-epithelial transition (MET) is regulated by the action of EMT transcription factors (TF) and miRNA. Some TF promote EM'T (such as Twist-related protein 1 - TWIST1, Zinc finger proteins SNAI1 and SNAI2, also referred to as SNAIL and SLUG, Zinc finger E-box-binding homeobox 1 and 2 - ZEB1, ZEB2), whereas others inhibit it (eg. ovo-like transcriptional repressors $1 / 2$, OVOL1/2, grainyhead like transcription factor 2, GRHL2) (Roca et al., 2013; Somarelli et al., 2016). Similarly, miRNA can inhibit EMT (miR-205 and miR-200 family) or promote it (miR-9 and miR-155) (Burk et al., 2008; Gregory et al., 2008; Kong et al., 2008; Gregory et al., 2011; Zhang \& $\mathrm{Ma}, 2012$ ).

Activation of EMT can also be studied in cancers by the analysis of EMT effectors (which are regulated by EMT TF/miRNAs) - downregulation of epithelial markers (e.g. E-cadherin, claudins, occludins) and upregulation of mesenchymal markers (e.g. vimentin, Ncadherin, fibronectin) (Jechlinger et al., 2003; Mani et al., 2008; Moreno-Bueno et al., 2008). It was also recognised that activation of EMT in cancer cells upregulates stem cell-like features and leads to therapy resistance (Mani et al., 2008). Despite contribution of EMT to the metastatic dissemination, EMT process needs to be reversed via MET in order to allow metastatic colonization at a distant site (Gao et al., 2012; Ocaña et al., 2012). This means that EMT activation is crucial for dissemination, but MET is required for re-establishing epithelial phenotype and colonization of a new niche (Aiello \& Kang, 2019). Therefore, transition between EMT and MET should provide plasticity necessary for dissemination from the primary tumour and colonization of a distant site. To test how EMT status of BC changes during metastatic progression, we have analysed EMT activation in non-colonizing PT $(\mathrm{N}-)$, colonizing PT $(\mathrm{N}+)$ and matched LNM, all in the context of two BC molecular subtypes (luminal and TNBC), which are known to differ in their EMT status.

\section{MATERIALS AND METHODS}

\section{Patients and tested samples}

Primary tumours (PT) of luminal and triple negative molecular subtypes and non-lobular histology $(\mathrm{N}=88)$, and matched lymph node metastases (LNM, N=41) from 88 non-metastatic BC patients were investigated. Patients were treated at the Medical University Hospital in Gdańsk between 2011 and 2013 according to the current standard of care. PT and LNM were removed during surgery and evaluated by a pathologist, followed by formalin fixation and paraffin embedding (FFPE), as described before (Markiewicz et al., 2014). Staging was performed according to the classification of American Joint Committee on Cancer version 7 staging manual, and tumour grade was assessed according to the modified Bloom-Richardson system. Molecular subtype was assessed according to St Gallen criteria (Goldhirsch et al., 2011) using oestrogen (ER) and progesterone (PR) receptors' status analysed by IHC and Allred scoring system; human epidermal growth factor receptor (HER2) status was analysed by immunohistochemistry (IHC) and fluorescent in situ hybridization in inconclusive cases $(2+$
IHC staining) and Ki-67. The ER, PR, and HER2 status were analysed during routine pathological examination of the samples, Ki-67 was tested by IHC on tissue microarrays (clone MIB-1, Dako, Copenhagen, Denmark), as described before (Markiewicz et al., 2014). All luminal tumours (luminal A, luminal B) were combined into one group, further described as the luminal subtype. Median age of the patients was 61 years and median follow up time (overall survival) was 4.1 years. Fifty-one percent $(45 / 88)$ of the patients had LNM (detailed clinico-pathological characteristics of patients are presented in Table S1 at https://ojs.ptbioch.edu.pl/index.php/abp/). The study was accepted by the Independent Ethics Committee of the Medical University of Gdańsk.

\section{Immunohistochemical analysis of PT and LNM}

Whole FFPE sections of PT and LNM were subjected to IHC staining of E-cadherin (clone $\mathrm{NCH} 38$, Dako), N-cadherin (clone 6G11, Dako) and Vimentin (VIM; clone V9, Dako), as described and presented in our previous work (Markiewicz et al., 2014). Activation of EMT (mesenchymal status of a sample) was defined as either E-cadherin loss in at least $10 \%$ of the cancer cells or acquisition of $\mathrm{N}$-cadherin or VIM in at least $10 \%$ of the cancer cells in the evaluated PT/LNM section. All three markers (E-cadherin, N-cadherin, VIM) had to be evaluated to assign EMT status of a sample, either epithelial (EPI) or mesenchymal (MES). Stroma content was assessed in tissue microarrays (TMA) comprised of five 1-mm diameter tumour samples per each patient (Markiewicz et al., 2014) based on hematoxylin-eosin staining. For each specimen, the maximum record of stroma content out of all evaluated and informative tissue cores was assigned for further analysis.

\section{Immune-related transcriptome profiling with nCounter technology}

Transcriptome analysis was performed for N- PT $(\mathrm{N}=11$, including 7 with epithelial and 4 with mesenchymal status), $\mathrm{N}+\mathrm{PT}(\mathrm{N}=23$, including 10 with epithelial and 13 with mesenchymal status) and LNM ( $N=11$, including 7 with epithelial and 4 with mesenchymal status) fragments, as previously described (Popeda et al., 2019). In brief, total RNA was extracted from FFPE blocks with RNeasy Mini Kit (Qiagen, Germantown, MD, USA), followed by preamplification and measurement of 730 immune-related genes' expression (nCounter PanCancer Immune Profiling Panel, NanoString Technologies, Seattle, WA, USA). Background correction and normalization were conducted with the nSolver 4.0 software (NanoString Technologies) according to the manufacturer's recommendations. Following low-expression gene filtering (global $\log 2$ mean count <6), 593 genes were included in the final analysis (Popeda et al., 2021). The NanoString platform is highly comparable with golden standard gene expression approach - RT-qPCR, and it might even outperform it on low-quality material like FFPE samples (Reis et al., 2011; Veldman-Jones et al., 2015). Raw expression data were submitted to NCBI GEO database under GSE180186 accession number.

\section{STATISTICAL ANALYSIS}

Data were analysed using the $\mathrm{R}$ statistical environment (version 3.6.1), GraphPad online tool and STATISTICA software (version 13.0, Statsoft, Cracow, Poland). Results were visualized with GraphPad Prism (version 8, Graph- 
Pad Software, Inc., San Diego, CA, USA) licensed for Medical University of Gdańsk.

Categorical variables were compared by Pearson's chi-squared and Fisher's exact test. Differences between quantitative values (gene expression levels between tissues of epithelial and mesenchymal phenotype) were estimated with Mann-Whitney $\mathrm{U}$ test, with $p$-values $<0.05$ considered as statistically significant. Differentially expressed gene (DEG) status was inferred based on statistical significance. Genes with median-based $\log 2 \mathrm{FC} \geq 1$ were considered as up- and genes with $\log 2 \mathrm{FC} \leq-1$ as down-regulated. For each type of tissue, DEGs were associated with GO BP and Reactome terms using Functional Annotation Tool by DAVID Bioinformatics Resources 6.8 (Huang et al., 2009a; Huang et al., 2009b). Kaplan-Meier curves for overall survival (OS) were compared using a log-rank test. Cohen's kappa was used to measure agreement between the EMT status of PT and LNM (Landis \& Koch, 1977).

\section{RESULTS}

\section{EMT activation during metastatic progression}

EMT activation was defined as either loss of E-cadherin or expression of VIM or N-cadherin (independently of the E-cadherin status) in the IHC staining of the LNM, as well as PT which have $(\mathrm{N}+)$ or have not colonized the lymph nodes $(\mathrm{N}-)$. With these criteria, EMT activation occurred in 35\% N-PT and 51\% N+ PT ( $p=0.13$ ), as well as in $32 \%$ of LNM (Fig. 1A). LNM showed a decreased activation of EMT in comparison to matched PT $(\mathrm{N}+, p=0.07$, Fig. 1A). When samples were analysed with subdivision into molecular subtypes, a large disproportion in the EMT activation status was noted between luminal and TNBC $(27 \%$ and $83 \%$, respectively; $p=0.01$, Fig. $1 \mathrm{~B}$ ) in the $\mathrm{N}-\mathrm{PT}$, but not in the $\mathrm{N}+\mathrm{PT}$
A

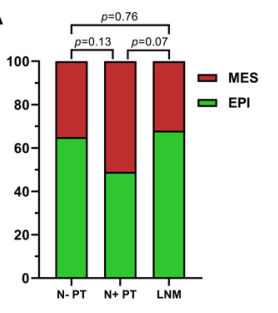

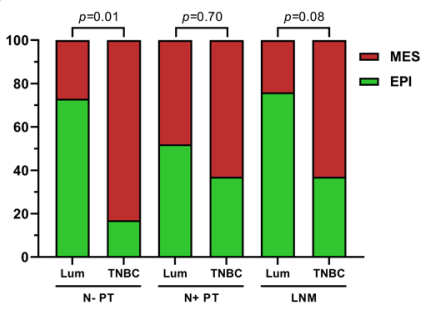

Figure 1. Activation of the EMT process in PT and LNM.

Percentages of epithelial (EPI) and mesenchymal (MES) phenotypes of PT which have not $(\mathrm{N}-)$ or have $(\mathrm{N}+)$ metastasized to the lymph nodes, as well as lymph node metastases themselves (LNM) presented without (A) and with subdivision to molecular subtypes (B). Significance levels were calculated with Pearson's chi-squared or Fisher's exact test.

(48\% in luminal and $63 \%$ in TNBC; $p=0.70$, Fig. 1B). In LNM, similarly to N- PT, a trend towards disproportion in EMT activation between molecular subtypes occurred (24\% in luminal and $63 \%$ in TNBC, $p=0.08$, Fig. 1B). In other words, the data show that during metastatic progression and lymph node colonization the EMT status of cancer cells changes, but to a different degree depending on the molecular subtype of the tumour. Luminal PT are more prone to turn on EMT during cancer progression, as shown by the increase in the mesenchymal status by $21 \%$ from $\mathrm{N}-$ to $\mathrm{N}+$ stage $(p=0.06$, Fig. S1A at https: $/ /$ ojs.ptbioch.edu.pl/index.php/abp/). For TNBC, the change in the EMT status between $\mathrm{N}-$ and $\mathrm{N}+$ was not significant ( $p=0.58$, Fig. S1B at https://ojs.ptbioch.edu. $\mathrm{pl} /$ index.php/abp/). During lymphatic colonization, luminal cancers turn off EMT - LNM showed a decreased mesenchymal status in comparison to matched PT $(\mathrm{N}+)$ (24\% in LNM vs $48 \%$ in PT, $p=0.04$, Fig. S1A at https://ojs.ptbioch.edu.pl/index.php/abp/), but no change in EMT status is observed in the TNBC subtype (mes-

A
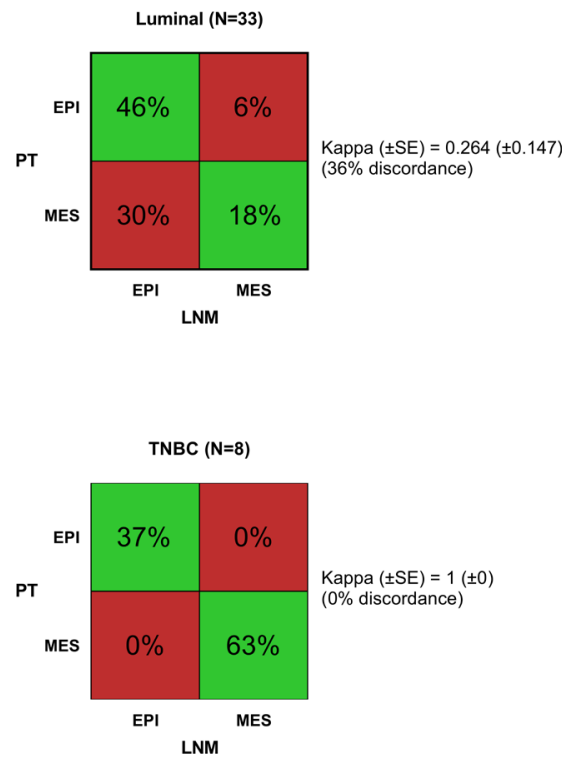

B

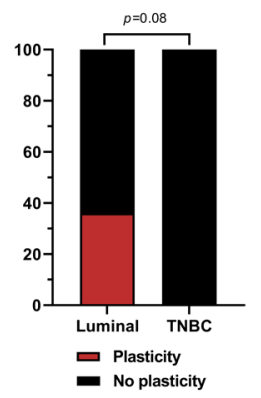

C

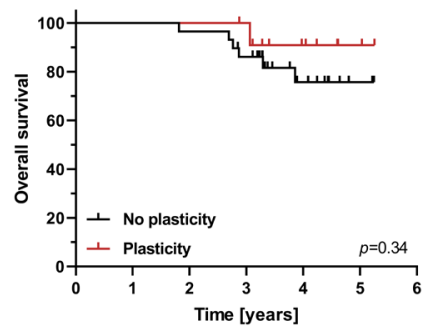

Figure 2. EMT plasticity in molecular subtypes of breast cancer.

Percentage of EMT phenotype changes between N+ PT and LNM of luminal and TNBC subtype (A; Cohen's kappa); occurrence of EMT phenotype change (EMT plasticity) between N+ PT and LNM in luminal and TNBC cancers (B; Fisher's exact test); prognostic significance of EMT plasticity in luminal and TNBC cancers - effect on overall survival of the patients ( $C$; log-rank test). 
A

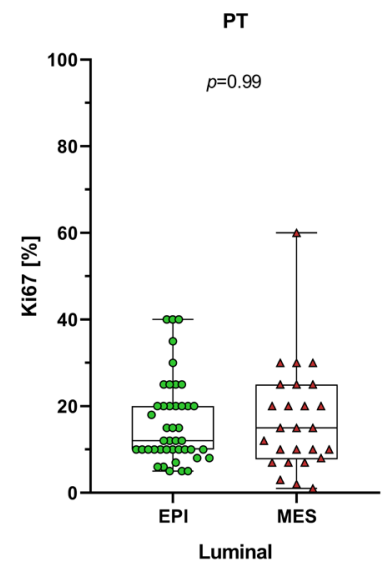

B

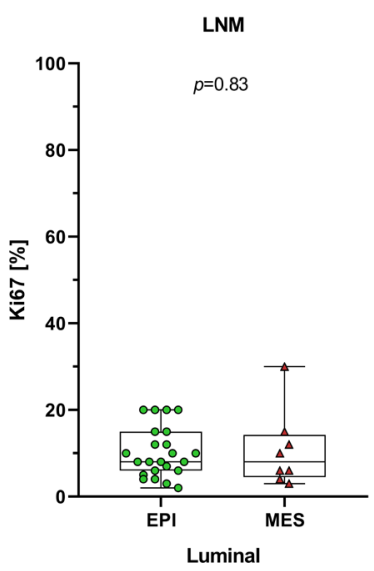

PT

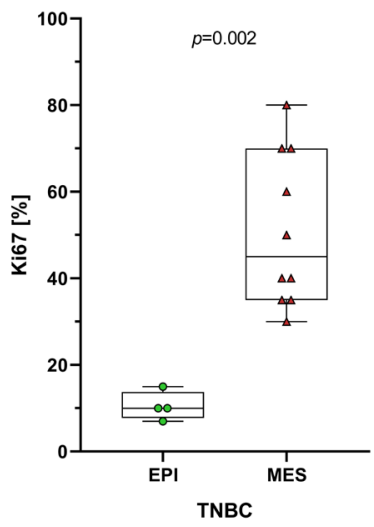

LNM

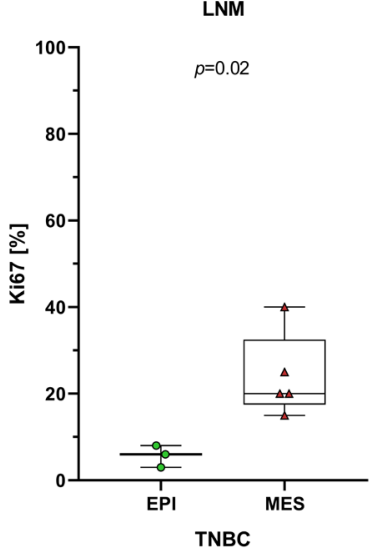

Figure 3. Cancer cell division rate in PT and LNM of luminal and TNBC subtypes.

Ki-67 staining in (A) primary tumours or (B) lymph node metastases. Significance levels were calculated with Mann-Whitney $U$ test.

Table 1. Correlation between clinico-pathological data of patients and occurrence of EMT plasticity between N+PT and LNM. $P$ was calculated with Pearson's chi-squared or Fisher's exact test.

\begin{tabular}{|c|c|c|c|c|c|}
\hline \multirow{2}{*}{ Variable } & \multirow{2}{*}{ Status } & \multicolumn{2}{|c|}{ EMT plasticity } & \multirow{2}{*}{$\%$ of samples with EMT plasticity } & \multirow{2}{*}{$p$} \\
\hline & & No & Yes & & \\
\hline \multirow{2}{*}{ Age } & $\leq 50$ years & 10 & 4 & 29 & \multirow{2}{*}{1.00} \\
\hline & $>50$ years & 19 & 8 & 30 & \\
\hline \multirow{2}{*}{ Tumour size $(\mathrm{T})$} & $\mathrm{T} 1-2$ & 26 & 11 & 30 & \multirow{2}{*}{1.00} \\
\hline & $\mathrm{T} 3$ & 2 & 1 & 33 & \\
\hline \multirow{2}{*}{ Number of involved lymph nodes } & $\leq 3$ & 19 & 4 & 17 & \multirow{2}{*}{0.06} \\
\hline & $>3$ & 10 & 8 & 44 & \\
\hline \multirow{2}{*}{ Grade } & $\mathrm{G} 1-2$ & 13 & 9 & 41 & \multirow{2}{*}{0.08} \\
\hline & G3 & 16 & 3 & 16 & \\
\hline \multirow{2}{*}{ ER } & Negative & 9 & 1 & 10 & \multirow{2}{*}{0.23} \\
\hline & Positive & 20 & 11 & 35 & \\
\hline \multirow{2}{*}{ PR } & Negative & 11 & 1 & 8 & \multirow{2}{*}{0.07} \\
\hline & Positive & 18 & 11 & 38 & \\
\hline \multirow{2}{*}{ HER2 } & Negative & 20 & 8 & 29 & \multirow{2}{*}{1.00} \\
\hline & Positive & 9 & 4 & 31 & \\
\hline
\end{tabular}


enchymal status in 63\% in LNM vs 63\% in PT, $p=1.00$, Fig. S1B at https://ojs.ptbioch.edu.pl/index.php/abp/).

\section{Clinical significance of EMT plasticity during metastatic colonization}

To evaluate more closely the change in the EMT status between N+ PT and LNM in different molecular subtypes, we evaluated the EMT plasticity which we defined as the occurrence of any EMT phenotypic switch between $\mathrm{N}+\mathrm{PT}$ and LNM compartment. In luminal cancers, $36 \%$ of the samples had discordant EMT activation status (Fig. 2A; usually a switch from mesenchymal status in PT to epithelial in LNM $-30 \%$ of the cases), whereas in the TNBC no PT-LNM discordance occurred (Fig. 2A). Calculated Cohen's kappa, which measures agreement between the EMT status of PT and LNM, showed perfect concordance in TNBC subtype $(\mathrm{k}=1)$, but fair agreement in luminal cancers $(x=0.264$, Fig. $2 \mathrm{~A})$. This indicates greater EMT plasticity in luminal than in TNBC tumours during lymphatic spread (Fig. 2B).
EMT plasticity was associated with the presence of progesterone receptors $(p=0.07)$, higher number of involved lymph nodes $(p=0.06)$, and lower tumour grade $(p=0.08)$, with $41 \%$ of the tumours showing EMT plasticity in the G1-G2 group, in comparison to $16 \%$ of the tumours with low differentiation (G3) ( $p=0.08$; Table 1). EMT plastic tumours showed better overall survival than tumours which did not change EMT status between N+ PT and LNM, though the results did not reach statistical significance $(p=0.34$, Fig. $2 \mathrm{C})$. At the same time, the EMT status of PT or LNM was not affecting the overall survival of the patients (Fig. S2A and S2B at https://ojs.ptbioch.edu.pl/index.php/abp/).

Interestingly, we observed that the EMT status of PT was related to differences in cell division rate depending on the molecular subtype of the tumour. In TNBC, mesenchymal phenotype of the PT resulted in 4.5-times higher cell division rate than in the epithelial phenotype (median $\mathrm{Ki}-67-45 \%$ in mesenchymal PT vs 10\% in epithelial PT, $p=0.002$; Fig. 3A). Similar observation was made in the LNM (median Ki-67 - 20\% in mesen-
A



C

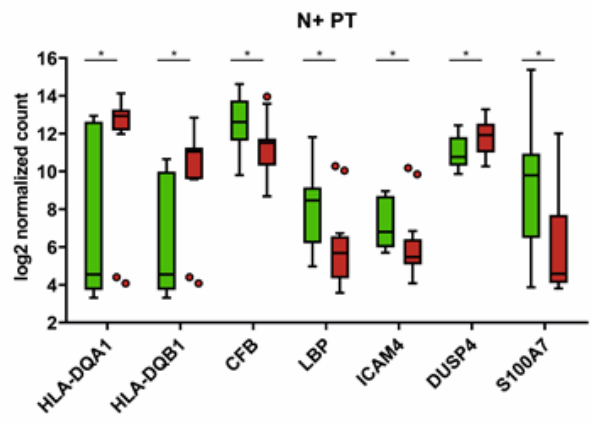

$\mathbf{E}$

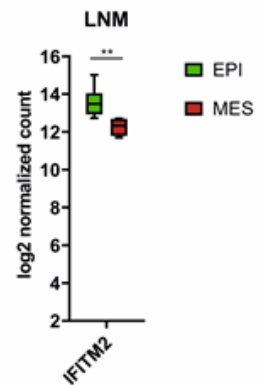

B

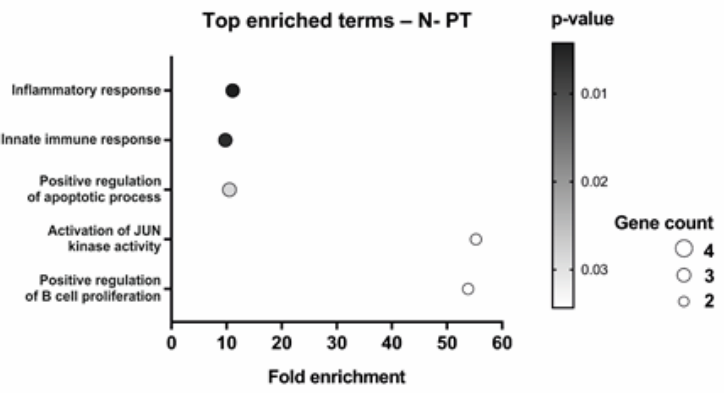

D

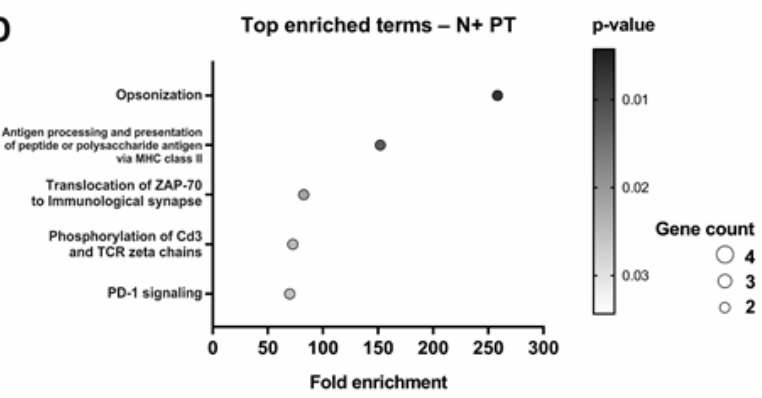

$\mathbf{F}$

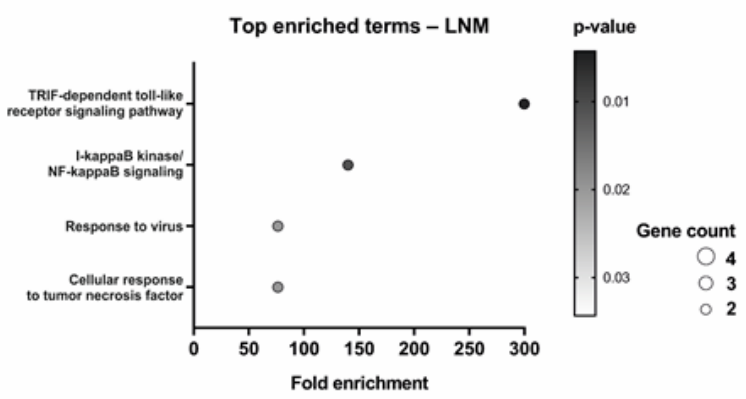

Figure 4. Differentially expressed immune-related genes between breast cancer samples of epithelial (EPI) and mesenchymal (MES) EMT phenotype assessed in PT N- (A), PT N+ (C) and LNM (E).

Only significantly up- $(\log 2 \mathrm{FC} \geq 1)$ and down-regulated (log2FC $\leq-1)$ DEGs are presented. Differences in median normalized counts between groups were analysed with the Mann-Whitney $U$ test; ${ }^{*} p<0.05,{ }^{* *} p<0.01$; the bars correspond to the interquartile range (IQR), the whiskers cover 1.5 IQR from the median. Top-enriched GO BP and Reactome terms among DEGs in each group of tissues - PT N- (B), PT $\mathrm{N}+(\mathrm{D})$ and LNM (F). These were established using the Functional Annotation Tool by DAVID Bioinformatics Resources 6.81. Terms are plotted against fold enrichment and arranged in ascending order by $p$-value; dot size represents the number of genes associated with a given term, while dot colour represents the $p$-value. 
chymal LNM vs $6 \%$ in epithelial LNM, $p=0.02$, Fig. 3B). No such differences were observed in PT or LNM of the luminal subtype (Fig. 3A and B).

\section{Tumour stroma profiling in PT and LNM in the context of EMT activation}

EMT can be induced by tumour microenvironment, and also by immune cells which secrete potent EMT inducers, like interferon gamma (IFN $\gamma$ ) (Cohen et al., 2015), tumour necrosis factor alpha (TNF $\alpha$ ) (Cohen et al., 2015), interleukin 6 (IL-6) (Cohen et al., 2015), and transforming growth factor beta (TGF $\beta$ ) (Pang et al., 2016; Kariche et al., 2019). Therefore, we have asked if there are differences in the immunotranscriptome of PT and LNM, which show EMT activation $v$ s those with no signs of EMT. The analysis was performed separately for $\mathrm{N}$ - and N+ PTs, as there were differences in EMT activation in these two groups as assessed by IHC (Fig. 1B), and also for N+ PT and LNM, which are an exact matched set originating from the same patients, therefore reflecting spatial and temporal changes of the tumour.

In the case of the N- PT, 5 genes were significantly down-regulated $(\log 2 \mathrm{FC} \leq-1)$ in mesenchymal, when compared to epithelial tumours, with just one gene (CD164) showing a significantly higher expression $(\log 2 \mathrm{FC} \geq 1)$ in mesenchymal N- PT (Fig. 4A). In terms of Gene Ontology (GO), a substantial change in inflammatory response was observed (Fig. 4B), however, the genes identified as differentially expressed between epithelial and mesenchymal N- PT showed an ambiguous role in inflammation, possibly reflecting heterogeneous composition of the tumour stroma. Sialomucin CD164, the only gene significantly upregulated in N- PT of the mesenchymal phenotype, was shown to drive the mesenchymal-epithelial transition when expressed in lung cancer cells (Chen et al., 2017), thus possibly playing a role in reverting aggressive mesenchymal phenotype of cancer cells to the epithelial phenotype.

In the N+ PT, the most significantly differentially expressed genes, with higher expression in mesenchymal PT, were MHC II molecules - HLA-DQA1 (log$2 \mathrm{FC}=8.38)$ and HLA-DQB1 $(\log 2 \mathrm{FC}=6.49$, Fig. 4C), which was also reflected in the GO analysis, showing top enriched terms being related to antigen processing and presentation or $\mathrm{T}$-cell associated signalling (Fig. 4D). At the same time, we have observed that mesenchymal PT from $\mathrm{N}+$ patients had higher stroma content than epithelial tumours (Fig. S3 at https://ojs. ptbioch.edu.pl/index.php/abp/), which could indicate that the mesenchymal phenotype of PT is associated with higher infiltration of antigen presenting cells.

LNM showed only one significantly differentially expressed gene, which had higher expression in the epithelial than mesenchymal samples - IFITM2 (Interferon Induced Transmembrane Protein 2, log$2 \mathrm{FC}=-1.11$, Fig. 4E). As IFTM2 is an interferoninducible gene, its increased expression suggests high interferon levels in epithelial LNM. Similarly, GO analysis showed TIR-domain-containing adapter-inducing IFN $\beta$ (TRIF)-dependent signalling pathway enrichment (Fig. 4F), which triggers production of type I interferon, especially interferon beta (IFN $\beta$ ) (Yamamoto et al., 2003).

Full list of differentially expressed genes and associated GO is shown in Table S2 and Table S3 at https:// ojs.ptbioch.edu.pl/index.php/abp/, respectively.

\section{DISCUSSION}

Development of metastasis remains the biggest challenge in management of cancer (Klein, 2020). Therefore, mechanisms employed by BC to spread, avoid apoptosis/senescence and colonize are intensively studied. Activation of the EMT program was found to contribute by a number of mechanisms to the malignancy of cancer cells, hence recognizing its role in clinical samples is required to pinpoint features important for metastatic progression in cancer patients.

In this study we evaluated how activation of the EMT program changes during cancer progression and metastatic colonization of the lymph nodes in the context of $\mathrm{BC}$ molecular subtypes. We have found that during cancer progression (comparison of $\mathrm{N}-$ and $\mathrm{N}+\mathrm{PT}$ ) the EMT status of PT changes; in luminal N- PT epithelial phenotype is clearly dominating, whereas in $\mathrm{N}-$ TNBC PT the mesenchymal phenotype is mostly observed. However, as PT progresses and seeds metastases to lymph nodes $(\mathrm{N}+$ stage), the disproportion in the EMT status between luminal and TNBC molecular subtypes disappears. To our knowledge, this is the first report showing the difference in EMT activation status in BC molecular subtypes in the context of cancer progression. TNBCs are known to have more mesenchymal phenotype than luminal cancers (Blick et al., 2008; Taube et al., 2010; Tan et al., 2014). However, our data show that these differences might be most prominent in PT that have not spread to the lymph nodes. In luminal $\mathrm{BC}$, activation of the EMT process might be more important for metastatic spread than in TNBC. In line with this finding, Savci-Heijink and others have found by profiling PT (classified to molecular subtypes by PAM50) of metastatic BC patients (which more closely resemble N+ PT) that luminal PT had an increased level of EMT markers $(84.6 \%$ of luminal A tumours, $65.1 \%$ of luminal B tumours, with the latter showing higher PR and cell cycle-related genes in comparison to luminal A tumours (Parker et al., 2009) than basal PT (25\%) (Savci-Heijink et al., 2019).

We also evaluated plasticity (change) in the EMT status between matched PT-LNM pairs and found that it only occurred in luminal tumours and was connected with better differentiation of PT. This could indicate that well differentiated tumours have greater ability to switch between phenotypes than high grade tumours. Our previous study on similar group of patients showed that well differentiated tumours have higher expression of EMT core regulator, TWIST1 (Markiewicz et al., 2014), which maintains EMT plastic state in breast cancer (Xu et al., 2017). Nevertheless, the occurrence of EMT plasticity between PT and LNM was also connected with a higher number of involved lymph nodes, which might suggest that the ability to change EMT status (mostly switching EMT off in LNM) could support dissemination and metastatic colonization within the lymphatic system. Ocaña and others also found that the metastatic spread within the lymphatic system might not require EMT activation (Ocaña et al., 2012), as the structure of the lymphatic compartment does not require intravasation of cells, which is normally enhanced by the EMT process. Therefore, EMT activation in the lymphatic system might not be required, but also might not be supported by the lymphatic environment. Indeed, our immunotranscriptome profiling of the LNM revealed that the epithelial phenotype of cancer cells might be forced by the TRIF-dependent signalling pathway, which is linked with the activation of type I interferon, like IFN $\beta$. As IFN $\beta$ signalling pathway was shown to be decreased in 
mammary cells with a mesenchymal phenotype (Doherty et al., 2017) and repression of aggressive stem cell phenotype in BC (Doherty et al., 2019), it would explain increased TRIF-dependent signalling in LNM with a less malignant epithelial phenotype.

Change in the EMT status of cancer cells might be a sign of cancer cells responsiveness to changes in the microenvironment, which can influence the EMT phenotype of the tumours (Quail \& Joyce, 2013; Hussain et al., 2020). During tumour progression changes in the microenvironment occur, which could exert different EMT-induction potential in cancer cells (Sica et al., 2008; Hussain et al., 2020; Westergaard et al., 2020). By profiling immunotranscriptome of the BC samples we showed that there was no overlap in differentially expressed genes between epithelial and mesenchymal phenotypes in neither of the compartments (PT vs LNM) and stages of tumour progression $(\mathrm{N}-\mathrm{PT}$ vs $\mathrm{N}+\mathrm{PT})$. This might reiterate heterogeneity in EMT-inducing factors, which can be different in dynamically changing tumour microenvironment (Whiteside, 2008; Binnewies et al., 2018). Two of the most significantly differentially expressed genes, increased in mesenchymal $\mathrm{N}+\mathrm{PT}$, were $H L A-D Q A 1$ and HLA-DQB1, being part of MHC class II antigen presentation complex. In vitro studies showed that macrophages, which are antigen presenting cells expressing MHC class II (Cruse et al., 2004), can induce EMT in luminal BC cell lines (Bednarczyk et al., 2018) and other cancers (Bonde et al., 2012).

Though the reverse to the EMT process of mesenchymal-epithelial transition is believed to be required for effective proliferation (Gao et al., 2012; Ocaña et al., 2012), this might not be the case in all molecular subtypes. We found that in TNBC, activation of the EMT program resulted in a significantly increased proliferation of PT and LNM. This would mean that in TNBC colonization can be triggered by EMT. Results presented by $\mathrm{Xu}$ et al. indicated that EMT induction in TNBC cancer cell line MDA-MB-231 induces Plasminogen Activator Inhibitor-1 (PAI-1) expression, which increases proliferation of cancer cells (Xu et al., 2018). Unfortunately, we were unable to profile TNBC with a Nanostring panel, thus immunological changes connected with these features could not be assessed. Another limitation of our study is a small sample size, especially for TNBC. Further studies on an extended set of samples are required to investigate the role of EMT in $\mathrm{BC}$ molecular subtypes in more detail. We predict that spatial transcriptomics could give more detailed insight into the heterogeneity of EMT status activation in PT/ LNM samples and will allow to study the interaction of cancer cells and the immune cells with higher resolution.

To summarize, our results show that in breast cancer EMT activation is connected with progression of luminal PT from non-colonizing $(\mathrm{N}-)$ to colonizing stage $(\mathrm{N}+)$, and in the TNBC EMT enhances proliferation of cancer cells. Moreover, our data underline the complexity of stroma-related factors in inducing/maintaining EMT in cancer cells at different stages of cancer progression, pointing to a role of antigen presenting cells in supporting mesenchymal phenotype of $\mathrm{N}-\mathrm{PT}$.

\section{REFERENCES}

Aiello NM, Kang Y (2019) Context-dependent EMT programs in cancer metastasis. J. Exp. Med. 216: 1016-1026. https://doi. org/10.1084/jem.20181827

Bednarczyk RB, Tuli NY, Hanly EK, Rahoma GB, Maniyar R, Mittelman A, Geliebter J, Tiwari RK (2018) Macrophage inflammatory factors promote epithelial-mesenchymal transition in breast cancer. Oncotarget 9: 24272-24282. https://doi.org/10.18632/oncotarget. 24917

Binnewies M, Roberts EW, Kersten K, Chan V, Fearon DF, Merad M, Coussens LM, Gabrilovich DI, Ostrand-Rosenberg S, Hedrick CC, Vonderheide RH, Pittet MJ, Jain RK, Zou W, Howcroft TK, Woodhouse EC, Weinberg RA, Krummel MF (2018) Understanding the tumor immune microenvironment (TIME) for effective therapy. Nat. Med. 24: 541-550. https://doi.org/10.1038/s41591-018-0014-x

Blick T, Widodo E, Hugo H, Waltham M, Lenburg ME, Neve RM, Thompson EW (2008) Epithelial mesenchymal transition traits in human breast cancer cell lines. Clin. Exp. Metastasis 25: 629-642. https://doi.org/10.1007/s10585-008-9170-6

Bonde AK, Tischler V, Kumar S, Soltermann A, Schwendener RA (2012) Intratumoral macrophages contribute to epithelial-mesenchymal transition in solid tumors. BMC Cancer 12: 35. https://doi. org/10.1186/1471-2407-12-35

Burk U, Schubert J, Wellner U, Schmalhofer O, Vincan E, Spaderna S, Brabletz T (2008) A reciprocal repression between ZEB1 and members of the miR-200 family promotes EMT and invasion in cancer cells. EMBO Rep. 9: 582-589. https://doi.org/10.1038/embor.2008.74

Cancer Genome Atlas Network (2012) Comprehensive molecular portraits of human breast tumours. Nature 490: 61-70. https:// doi. org/10.1038/nature11412

Chen WL, Huang AF, Huang SM, Ho CL, Chang YL, Chan JY (2017) CD164 promotes lung tumor-initiating cells with stem cell activity and determines tumor growth and drug resistance via Akt/mTOR signaling. Oncotarget 8: 54115-54135. https://doi.org/10.18632/oncotarget.11132

Cohen EN, Gao H, Anfossi S, Mego M, Reddy NG, Debeb B, Giordano A, Tin S, Wu Q, Garza RJ, Cristofanilli M, Mani SA, Croix DA, Ueno NT, Woodward WA, Luthra R, Krishnamutry S, Reuben JM (2015) Inflammation mediated metastasis: immune induced epithelial-to-mesenchymal transition in inflammatory breast cancer cells. PLoS One 10: e0132710. https://doi.org/10.1371/journal.pone. 0132710

Cruse J, Lewis R, Wang H (2004) Antigen presentation. In Immunology Guidebook. pp 267-276. Academic Press. https://doi.org/10.1016/ B978-0-12-198382-6.X5022-5

Doherty MR, Cheon H, Junk DJ, Vinayak S, Varadan V, Telli ML, Ford JM, Stark GR, Jackson MW (2017) Interferon-beta represses cancer stem cell properties in triple-negative breast cancer. Proc. Natl. Acad. Sci. U. S. A. 114: 13792-13797. https://doi. org/10.1073/pnas.1713728114

Doherty MR, Parvani JG, Tamagno I, Junk DJ, Bryson BL, Cheon HJ, Stark GR, Jackson MW (2019) The opposing effects of interferonbeta and oncostatin-M as regulators of cancer stem cell plasticity in triple-negative breast cancer. Breast Cancer Res. 21: 54. https://doi. org/10.1186/s13058-019-1136-x

Felipe Lima J, Nofech-Mozes S, Bayani J, Bartlett JM (2016) EMT in breast carcinoma - a review. J. Clin. Med. 5: 65. https://doi. org/10.3390/jcm5070065

Gao D, Joshi N, Choi H, Ryu S, Hahn M, Catena R, Sadik H, Argani P, Wagner P, Vahdat LT, Port JL, Stiles B, Sukumar S, Altorki NK, Rafii S, Mittal V (2012) Myeloid progenitor cells in the premetastatic lung promote metastases by inducing mesenchymal to epithelial transition. Cancer Res. 72: 1384-1394. https://doi.org/10.1158/00085472.CAN-11-2905

Goldhirsch A, Wood WC, Coates AS, Gelber RD, Thürlimann B, Senn HJ (2011) Strategies for subtypes-dealing with the diversity of breast cancer: highlights of the St. Gallen International Expert Consensus on the Primary Therapy of Early Breast Cancer. Ann. Oncol. 22: 1736-1747. https://doi.org/10.1093/annonc/mdr304

Gregory PA, Bert AG, Paterson EL, Barry SC, Tsykin A, Farshid G, Vadas MA, Khew-Goodal Y, Goodal GJ (2008) The miR-200 family and miR-205 regulate epithelial to mesenchymal transition by targeting ZEB1 and SIP1. Nat. Cell Biol. 10: 593-601. https://doi. org/10.1038/ncb1722

Gregory PA, Bracken CP, Smith E, Bert AG, Wright JA, Roslan S, Morris M, Wyatt L, Farshid G, Lim YY, Lindeman GJ, Shannon MF, Drew PA, Khew-Goodal Y, Goodal GJ (2011) An autocrine TGF-beta/ZEB/miR-200 signaling network regulates establishment and maintenance of epithelial-mesenchymal transition. Mol. Biol. Cell 22: 1686-1698. https://doi.org/10.1091/mbc.E11-02-0103

Hennigs A, Riedel F, Gondos A, Sinn P, Schirmacher P, Marmé F, Jäger D, Kauczor HU, Stieber A, Lindel K, Debus J, Golatta M, Shütz F, Sohn C, Heil J, Schneeweiss A (2016) Prognosis of breast cancer molecular subtypes in routine clinical care: A large prospective cohort study. BMC Cancer 16: 734. https://doi.org/10.1186/ s12885-016-2766-3

Huang DW, Sherman BT, Lempicki RA (2009a) Bioinformatics enrichment tools: paths toward the comprehensive functional analysis of large gene lists. Nucleic Acids Res. 37: 1-13. https://doi.org/10.1093/ nar/gkn923

Huang DW, Sherman BT, Lempicki RA (2009b) Systematic and integrative analysis of large gene lists using DAVID bioinformat- 
ics resources. Nat. Protoc. 4: 44-57. https://doi.org/10.1038/ nprot. 2008.211

Hussain S, Peng B, Cherian M, Song JW, Ahirwar DK, Ganju RK (2020) The roles of stroma-derived chemokine in different stages of cancer metastases. Front. Immunol. 11: 598-532. https://doi, org/10.3389/fimmu.2020.598532

Jechlinger M, Grunert S, Tamir IH, Janda E, Lüdemann S, Waerner T, Seither P, Weith A, Beug H, Kraut N (2003) Expression profiling of epithelial plasticity in tumor progression. Oncogene 22: 7155-7169. https://doi.org/10.1038/sj.onc.1206887

Kariche N, Moulaï N, Sellam LS, Benyahia S, Ouahioune W, Djennaoui D, Touil-Boukoffa C, Bourouba M (2019) Expression analysis of the mediators of epithelial to mesenchymal transition and early risk assessment of therapeutic failure in laryngeal carcinoma. J. Oncol. 2019: 5649846. https://doi.org/10.1155/2019/5649846

Kast K, Link T, Friedrich K, Petzold A, Niedostatek A, Schoffer O, Werner C, Klug SJ, Werner A, Gatzweiler A, Richter B, Baretton G, Wimberger P (2015) Impact of breast cancer subtypes and patterns of metastasis on outcome. Breast Cancer Res. Treat. 150: 621629. https://doi.org/10.1007/s10549-015-3341-3

Katsuno Y, Meyer DS, Zhang Z, Shokat KM, Akhurst RJ, Miyazono K, Derynck R (2019) Chronic TGF- $\beta$ exposure drives stabilized EMT, tumor stemness, and cancer drug resistance with vulnerability to bitopic mTOR inhibition. Sci. Signal. 12: 570 . https://doi. org/10.1126/scisignal.aau8544

Klein CA (2020) Cancer progression and the invisible phase of metastatic colonization. Nat. Rev. Cancer 20: 681-694. https://doi. org/10.1038/s41568-020-00300-6

Kong W, Yang H, He L, Zhao JJ, Coppola D, Dalton WS, Cheng JQ (2008) MicroRNA-155 is regulated by the transforming growth factor beta/Smad pathway and contributes to epithelial cell plasticity by targeting RhoA. Mol. Cell Biol. 28: 6773-6784. https://doi. org/10.1128/MCB.00941-08

Lamouille S, Xu J, Derynck R (2014) Molecular mechanisms of epithelial-mesenchymal transition. Nat. Rev. Mol. Cell Biol. 15: 178-196. https://doi.org/10.1038/nrm3758

Landis JR, Koch GG (1977) The measurement of observer agreement for categorical data. Biometrics 33: 159-174. https://doi. org $/ 10.2307 / 2529310$

Mani SA, Guo W, Liao MJ, Eaton EN, Ayyanan A, Zhou AY, Brooks M, Reinhard F, Zhang CC, Shipitsin M, Campbell LL, Polyak K, Brisken C, Yang J, Weinberg RA (2008) The epithelial-mesenchymal transition generates cells with properties of stem cells. Cell 133: 704-715. https://doi.org/10.1016/j.cell.2008.03.027

Markiewicz A, Wełnicka-Jaśkiewicz M, Seroczyńska B, Skokowski J, Majewska H, Szade J, Żaczek AJ (2014) Epithelial-mesenchymal transition markers in lymph node metastases and primary breast tumors - relation to dissemination and proliferation. Am. J. Transl. Res. 6: 793-808

Morel AP, Lièvre M, Thomas C, Hinkal G, Ansieau S, Puisieux A (2008) Generation of breast cancer stem cells through epithelial-mesenchymal transition. PLoS One 3: e2888. https://doi. org/10.1371/journal.pone.0002888

Moreno-Bueno G, Portillo F, Cano A (2008) Transcriptional regulation of cell polarity in EMT and cancer. Oncogene 27: 6958-6969. https://doi.org/10.1038/onc.2008.346

Ocaña OH, Córcoles R, Fabra A, Moreno-Bueno G, Acloque H, Vega S, Barrallo-Gimeno A, Cano A, Nieto MA (2012) Metastatic colonization requires the repression of the epithelial-mesenchymal transition inducer Prrx1. Cancer Cell 22: 709-724. https://doi. org/10.1016/j.ccr.2012.10.012

Pang MF, Georgoudaki AM, Lambut L, Johansson J, Tabor V, Hagikura K, Jin Y, Jansson M, Alexander JS, Nelson CM, Jakobsson L, Betsholtz C, Sund M, Karlson MCI, Fuxe J (2016) TGF- $\beta 1$-induced EMT promotes targeted migration of breast cancer cells through the lymphatic system by the activation of CCR7/CCL21-mediated chemotaxis. Oncogene 35: 748-760. https://doi.org/10.1038/ onc. 2015.133

Parker JS, Mullins M, Cheang MC, Leung S, Voduc D, Vickery T, Davies S, Fauron C, Xiaping H, Hu Z, Quackenbush JF, Stijleman IJ, Palazzo J, Marron JS, Nobel AB, Mardis E, Nielsen TO, Ellis MJ, Perou MJ, Bernard PS (2009) Supervised risk predictor of breast cancer based on intrinsic subtypes. J. Clin. Oncol. 27: 1160-1167. https://doi.org/10.1200/JCO.2008.18.1370

Popeda M, Markiewicz A, Stokowy T, Szade J, Niemira M, Kretowski A, Bednarz-Knoll N, Żaczek AJ (2021) Reduced expression of innate immunity-related genes in lymph node metastases of luminal breast cancer patients. Sci. Rep. 11: 5097. https://doi.org/10.1038/ s41598-021-84568-0

Popeda M, Stokowy T, Bednarz-Knoll N, Jurek A, Niemira M, Bielska A, Kretowski A, Kalinowski L, Szade J, Markiewicz A, Żaczek AJ (2019) NF-kappa B signaling-related signatures are connected with the mesenchymal phenotype of circulating tumor cells in non-metastatic breast cancer. Cancers 11: 1961. https://doi.org/10.3390/cancers11121961
Quail DF, Joyce JA (2013) Microenvironmental regulation of tumor progression and metastasis. Nat. Med. 19: 1423-1437. https://doi. org/10.1038/nm.3394

Reis PP, Waldron L, Goswami RS, Xu W, Xuan Y, Perez-Ordonez B, Gullane P, Irish J, Jurisica I, Kamel-Reid S (2011) mRNA transcript quantification in archival samples using multiplexed, color-coded probes. BMC Biotechnol. 11: 46. https://doi.org/10.1186/1472-675011-46

Roca H, Hernandez J, Weidner S, McEachin RC, Fuller D, Sud S, Schumann T, Wilkinson JE, Zaslavsky A, Li H, Maher CA, Daignault-Newton S, Healy PN, Pienta KJ (2013) Transcription factors OVOL1 and OVOL2 induce the mesenchymal to epithelial transition in human cancer. PLoS One 8: e76773. https://doi. org/10.1371/journal.pone.0076773

Sarrió D, Rodriguez-Pinilla SM, Hardisson D, Cano A, Moreno-Bueno G, Palacios J (2008) Epithelial-mesenchymal transition in breast cancer relates to the basal-like phenotype. Cancer Res. 68: 989-997. https://doi.org/10.1158/0008-5472.CAN-07-2017

Savci-Heijink CD, Halfwerk H, Hooijer GKJ, Koster J, Horlings HM, Meijer SL, van de Vijver MJ (2019) Epithelial-to-mesenchymal transition status of primary breast carcinomas and its correlation with metastatic behavior. Breast Cancer Res. Treat. 174: 649-659. https:// doi.org/10.1007/s10549-018-05089-5

Shibue T, Weinberg RA (2017) EMT, CSCs, and drug resistance: the mechanistic link and clinical implications. Nat. Rev. Clin. Oncol. 14: 611-629. https://doi.org/10.1038/nrclinonc.2017.44

Sica A, Larghi P, Mancino A, Rubino L, Porta C, Totaro MG, Rimoldi M, Biswas SK, Allavena P, Mantovani A (2008) Macrophage polarization in tumour progression. Semin. Cancer Biol. 18: 349-355. https://doi.org/10.1016/j.semcancer.2008.03.004

Somarelli JA, Shetler S, Jolly MK, Wang X, Bartholf Dewitt S, Hish AJ, Gilja S, Eward WC, Ware KE, Levine H, Armstrong AJ, Garcia-Blanco MA (2016) Mesenchymal-epithelial transition in sarcomas is controlled by the combinatorial expression of MicroRNA 200s and GRHL2. Mol. Cell Biol. 36: 2503-2513. https://doi. org/10.1128/MCB.00373-16

Sánchez-Tilló E, de Barrios O, Siles L, Cuatrecasas M, Castells A, Postigo A (2011) $\beta$-catenin/TCF4 complex induces the epithelial-to-mesenchymal transition (EMT)-activator ZEB1 to regulate tumor invasiveness. Proc. Natl. Acad. Sci. U. S. A. 108: 19204-19209. https://doi.org/10.1073/pnas.1108977108

Tan TZ, Miow QH, Miki Y, Noda T, Mori S, Huang RY, Thiery JP(2014) Epithelial-mesenchymal transition spectrum quantification and its efficacy in deciphering survival and drug responses of cancer patients. EMBO Mol. Med. 6: 1279-1293. https://doi.org/10.15252/ emmm.201404208

Taube JH, Herschkowitz JI, Komurov K, Zhou AY, Gupta S, Yang J, Hartwell K, Onder TT, Gupta PB, Evans KW, Hollier BG, Ram PT, Lander ES, Rosen JM, Weinberg RA, Mani SA (2010) Core epithelial-to-mesenchymal transition interactome gene-expression signature is associated with claudin-low and metaplastic breast cancer subtypes. Proc. Natl. Acad. Sci. U. S. A. 107: 15449-15454. https:// doi.org/10.1073/pnas.1004900107

Thiery JP (2002) Epithelial-mesenchymal transitions in tumour progression. Nat. Rev. Cancer 2: 442-454. https://doi.org/10.1038/nrc822

Veldman-Jones MH, Brant R, Rooney C, Geh C, Emery H, Harbron CG, Wappett M, Sharpe A, Dymond M, Barrett JC, Harrington EA, Marshall G (2015) Evaluating robustness and sensitivity of the NanoString technologies nCounter platform to enable multiplexed gene expression analysis of clinical samples. Cancer Res. 75: 25872593. https://doi.org/10.1158/0008-5472.CAN-15-0262

Westergaard MCW, Milne K, Pedersen M, Hasselager T, Olsen LR, Anglesio MS, Borch TH, Kennedy M, Briggs G, Ledoux S, Kreuzinger C, von der Drecken I, Donia M, Castillo-Tong DC, Nelson $\mathrm{BH}$, Svane IM (2020) Changes in the tumor immune microenvironment during disease progression in patients with ovarian cancer. Cancers 12: 3828. https://doi.org/10.3390/cancers12123828

Whiteside TL (2008) The tumor microenvironment and its role in promoting tumor growth. Oncogene 27: 5904-5912. https://doi. org/10.1038/onc. 2008.271

Xu J, Zhang W, Tang L, Chen W, Guan X (2018) Epithelial-mesenchymal transition induced PAI-1 is associated with prognosis of triple-negative breast cancer patients. Gene 670: 7-14. https://doi. org/10.1016/j.gene.2018.05.089

Xu Y, Lee DK, Feng Z, Bu W, Li Y, Liao L, Xu J (2017) Breast tumor cell-specific knockout of Twist1 inhibits cancer cell plasticity, dissemination, and lung metastasis in mice. Proc. Natl. Acad. Sci. U. S. A. 114: 11494-11499. https://doi.org/10.1073/pnas.1618091114

Yamamoto M, Sato S, Hemmi H, Hoshino K, Kaisho T, Sanjo H, Takeuchi O, Sugiyama M, Okabe M, Takeda K, Akira S (2003) Role of adaptor TRIF in the MyD88-independent toll-like receptor signaling pathway. Science 301: 640-643. https://doi.org/10.1126/science. 1087262

Zhang J, Ma L (2012) MicroRNA control of epithelial-mesenchymal transition and metastasis. Cancer Metastasis Rev. 31: 653-662. https:// doi.org/10.1007/s10555-012-9368-6 